\title{
Notes from the Packaging Laboratory: Polylactic Acid -- An Exciting New Packaging Material ${ }^{1}$
}

\section{Melisa Balkcom, Bruce Welt, Kenneth Berger ${ }^{2}$ \\ Introduction}

Everyday, landfills all over the United States are reaching their capacities, and new landfills are opened. Americans are throwing away truckloads of trash every year -- about 1500 pounds of waste per year for every person.

Plastic polymers account for about 20 percent (by volume) of landfill space. Many cities have run out of space to dispose of their trash and are paying to ship their trash to remote locations. It is only a matter of time until we run completely out of room for our trash on earth. Not only are we creating so much trash that we don't know what to do with it, we are also depleting our finite natural resources in the process. It is estimated that known global resources of oil will run dry in 80 years, natural gas in 70 years and coal in 700 years, but the economic impact of the depletion could hit much sooner; since prices will likely soar as resources are depleted (5). It is clear that researchers need to work toward replacing fossil fuel resources with renewable resources as both fuel and raw materials for our many petroleum-based products (5). Headway is being made with a polymer called Polylactic Acid (PLA), an affordable, recyclable, innovative packaging material made from renewable resources.

\section{What is Polylactic Acid?}

Polylactic acid (PLA) is a biodegradable polymer derived from lactic acid. It is a highly versatile material and is made from $100 \%$ renewable resources like corn, sugar beets, wheat and other starch-rich products. Polylactic acid exhibits many properties that are equivalent to or better than many petroleum-based plastics, which makes it suitable for a variety of applications.

It is important that PLA compares well with other popular plastics already used for packaging. It is clear and naturally glossy like the polystyrene used in "blister packs" for products such as batteries, toys, and many others (3). PLA is resistant to moisture and grease. It has flavor and odor barrier characteristics similar to the popular plastic polyethylene terephthalate (PET) used for soft drinks and many other food products $(6,13)$. Tensile strength and modulus of elasticity of PLA is also comparable to PET (6).

1. This document is ABE339, one of a series of the Agricultural and Biological Engineering Department, Florida Cooperative Extension Service, Institute of Food and Agricultural Sciences, University of Florida. First published December 2002. Please visit the EDIS Web site at http://edis.ifas.ufl.edu.

2. Melisa Balkcom, associate engineer, TNT Logistics North America, Jacksonville, Florida; Bruce Welt, assistant professor, and Kenneth R. Berger, assistant professor, Agricultural and Biological Engineering Department, Institute of Food and Agricultural Sciences, University of Florida, Gainesville.

Use of commercial trade names in this publication does not imply any endorsement of specific products or companies by the Institute of Food and Agricultural Sciences or the University of Florida.

The Institute of Food and Agricultural Sciences is an equal opportunity/affirmative action employer authorized to provide research, educational information and other services only to individuals and institutions that function without regard to race, color, sex, age, handicap, or national origin. For information on obtaining other extension publications, contact your county Cooperative Extension Service office. Florida Cooperative Extension Service/Institute of Food and Agricultural Sciences/University of Florida/Christine Taylor Waddill, Dean. 
PLA can be formulated to be either rigid or flexible and can be copolymerized with other materials (6). Polylactic acid can be made with different mechanical properties suitable for specific manufacturing processes, such as injection molding, sheet extrusion, blow molding, thermoforming, film forming and fiber spinning using most conventional techniques and equipment (4).

PLA is a nonvolatile, odorless polymer and is classified as GRAS (generally recognized as safe) by the Food and Drug Administration in the United States (3).

\section{History}

Polylactic acid is not a new material. It has been around for decades. In 1932, Wallace Carothers, a scientist for Dupont, produced a low molecular weight product by heating lactic acid under a vacuum. In 1954, after further refinements, Dupont patented Carothers' process (8).

Due to high costs, the focus since then has been mainly on the manufacture of medical grade sutures, implants and controlled drug release applications. The cost of production of the monomer has been a deterrent to widespread development of the polymer. Recently, there have been advances in fermentation of glucose, which turns the glucose into lactic acid. This has dramatically lowered the cost of producing lactic acid and significantly increased interest in the polymer.

Cargill, Incorporated, was one of the first companies to extensively develop polylactic acid polymers. Cargill began researching PLA production technology in 1987, and began production of pilot plant quantities in 1992. In 1997, after a 15-month joint investigation, Cargill formed a joint venture with Dow Chemical Company, Inc., creating Cargill Dow Polymers LLC (CDP). The joint venture is dedicated to further commercializing PLA polymers (6) and formally launched Nature WorksTM PLA technology in 2001. Construction was recently completed on a large-scale PLA manufacturing facility in Blair, Nebraska (9).

The Nebraska facility will be capable of producing up to 300 million pounds (140,000 metric tons) of PLA per year, using 40,000 bushels of corn per day (9). Production is expected to more than triple -- to one billion pounds -- by 2007 (13). There are also plans to construct an additional plant in Europe sometime in the near future (4). By all indications, the opening of CDP's plant in Nebraska will significantly expand the market for polylactic acid polymers by making PLA available on a commercial scale.

\section{What Is PLA Used For?}

Polylactic acid is a versatile polymer that has many potential uses, including many applications in the textile and medical industries as well as the packaging industry.

Four types of polylactic acid are available for packaging purposes: PLA polymers 4041D, 4031D, 1100D, and 2000D.

Polymer 4041D is a general purpose film. It is "biaxially oriented", a property that gives it stability at temperatures up to 265 degrees F (130 degrees C). Polymer 4031D is also a biaxially oriented film for high temperature applications (300 degrees F or 150 degrees C). According to CDP, 4041D and 4031D offer excellent optical properties, good machinability and excellent twist and deadfold characteristics. These polymers are expected to be offered in common pellet form, which should allow for rapid adoption with conventional extruders (8).

Polymer $1100 \mathrm{D}$ is a thermoplastic resin designed for extrusion coating on paper. According to CDP, $1100 \mathrm{D}$ processes easily on conventional extrusion coating equipment at a lower melt extrusion temperature than polyethylene coatings. Paper and board coated in this resin can be heat-sealed on typical equipment. Potential applications for PLA1100D include, but are not limited to, lawn and leaf bags, hot and cold drinking cups, picnic plates, bowls, straws, fried food boxes, frozen vegetable packaging, and liquid food packaging.

Polymer 2000D is a thermoplastic resin designed for extrusion and thermoforming applications. It is a clear extrusion sheet grade, and like CDP's other PLA polymers, uses conventional techniques and equipment. Potential uses for 2000D include dairy 
containers, food serviceware, transparent food containers, blister packs, and cold drink cups (8).

The CDP packaging division is currently working with six development partners including Bimo Italia S.P.A., Mitsubishi Plastics, Inc, and Biocorp USA (2). Biocorp gained recognition by supplying all of the compostable cutlery and biodegradable bags used at the 2000 summer Olympic games in Sydney, Australia. This allowed the recycling and/or composting of 75 percent, or more than 5.7 million pounds, of waste that was generated during the games. CDP hopes that consumers will soon be seeing PLA polymers everywhere, from fresh fruit containers and candy wrappers to coffee packs and milk and yogurt containers (8).

Polylactic acid also has many potential uses in fibers and non-wovens. It is easily converted into a variety of fiber forms using conventional melt-spinning processes. Spunbound and meltblown non-wovens as well as monocomponent, bicomponent, continuous (flat and textured) and stable fibers are all easily produced. These materials have many attributes that make them attractive for many traditional applications. Polylactic acid polymers are more hydrophilic than PET, have a lower density, and have excellent crimp and crimp retention. Shrinkage of PLA materials and thermal bonding temperatures are readily controllable. These polymers tend to be stable to ultra-violet light resulting in fabrics that show little fading. They also offer low flammability and smoke generation characteristics. Major applications for PLA fibers and non-wovens include, but are not limited to, clothing and furnishings such as drapes, upholstery and covers. Some exciting potential applications include household and industrial wipes, diapers, feminine hygiene products, disposable garments, and UV resistant fabrics for exterior use (awnings, ground cover, etc.) among others (8).

Polylactic acid has already become an important material in the medical industry, where it has been in use for over 25 years. Polylactic acid is a biodegradable, bioresorbable polymer (which means that it can be assimilated by a biological system). Since PLA can be assimilated by the body, it has found important applications in sustained release drug delivery systems. Its mechanical properties and absorbability make PLA polymer an ideal candidate for implants in bone or soft tissue (facial traumatology, orthopedic surgery, ophthalmology, orthodontics, local implants for controlled release of anti-cancer drugs), and for resorbable sutures (eye surgery, conjunctional surgery, surgery of the chest and abdomen). The mechanical, pharmaceutical and bioabsorption characteristics are dependent on controllable parameters such as chemical composition and molecular weight of the polymer. The time frame for resorbtion of the polymer may be as little as a few weeks to a few years and can be regulated by use of different formulations and the addition of radicals on its chains (1).

\section{How Is PLA Made?}

The starting material for polylactic acid is starch from a renewable resource such as corn. Corn is milled, which separates starch from the raw material. Unrefined dextrose is then processed from the starch. Dextrose is turned into lactic acid using fermentation, similar to that used by beer and wine producers.

Turning the lactic acid into a polymer plastic takes some specialized chemistry. Through a chemical process called condensation, two lactic acid molecules are converted into one cyclic molecule called a lactide. This lactide is purified through vacuum distillation. A solvent-free melt process causes the ring-shaped lactide polymers to open and join end-to-end to form long chain polymers. A wide range of products that vary in molecular weight and crystallinity can be produced, allowing the PLA to be modified for a variety of applications (2).

\section{How Is PLA "Unmade"?}

Polylactic acid polymers are fully compostable in commercial composting facilities. With proper equipment, PLA can be converted back to monomer, which then can be converted back into polymers. Alternatively, PLA can be biodegraded into water, carbon dioxide, and organic material (10). At the end of a PLA-based product's life cycle, a product made from PLA can be broken down into its simplest parts so that no sign of the original product remains (2). 


\section{Is PLA as Good as It Seems?}

Polylactic acid seems to be an incredible product. It is biodegradable, so PLA waste can be diverted from landfills. It is also made from renewable resources, so raw material should always be available. Some people think the promise of PLA sounds too good to be true.

One major criticism of the polymer occurs during its biological breakdown phase. PLA releases carbon dioxide and methane during this process. These are generally recognized as two heat-trapping greenhouse gases that are being targeted for reduced emissions standards by international committees. Another criticism is that fossil fuels are still needed to produce PLA. Although fossil fuels are not used in the polymer itself, they are needed to power the processes involved in plant harvests and chemical production. Skeptics also warn that biodegradable plastics degrade too slowly in to make a substantial difference to waste streams.

In response to these concerns, PLA supporters acknowledge that fossil fuels are being used to produce the plastic, but state that this process requires between 20 and 50 percent less fossil resources than making plastics from petroleum. Also, while petroleum is the primary resource for conventional plastic production, coal and natural gas are mainly used in the plastic-from-plant making process. Since plant-based methods involve switching from a less abundant resource (oil) to a more abundant one (coal), it is argued that this is a step toward sustainability.

Patrick Gruber, the Vice President of Technology for CDP, responded to questions about the energy usage concerns: "Not only are we developing production methods that require less energy, we are also investigating more efficient ways to generate energy, including cogeneration and use of renewable fuels such as plant material, or biomass. We are also pursuing alternative raw materials for PLA. Using fermentable sugars from corn stover would allow a second crop to be harvested from the same land used to grow corn grain.

Lactic acid, and therefore PLA, can also be derived from wheat, beets and other crops best suited to particular climates." He also stated, "It is important to realize that our PLA-manufacturing technology is only ten years old and has yet to profit from the nearly 100 years during which petrochemical-plastic manufacturing has been improving." As our scientists and engineers optimize the production of PLA, we expect to reduce the energy requirements of our second and third manufacturing facilities, targeted for construction as early as 2004 , by as much as 50 percent (5)."

In response to the argument about release of greenhouse gases, PLA and plant-based plastic supporters argue that plants process carbon dioxide as they are growing and living so the carbon dioxide that they release into the atmosphere as they are degrading is reused by new plants, leading to no net increase in carbon dioxide gases in the atmosphere.

Supporters also note that in order for these plastics to degrade they need to be properly composted and not simply sent to a typical landfill with nondegradable materials. This will take a movement similar to that of the "recycling movement," and also cost money to build more composting facilities and to educate the public. An advantage though is that yard and agricultural waste, which is a much larger solid waste burden than polymers, can also be composted, which would further reduce the amount of material that is sent to the landfill (12).

The technology for this kind of industrial-scale composting of community waste is being developed at the University of Florida. Called SEBAC for "sequential batch anaerobic composting", this method could be used to turn a significant amount of wastes into usable compost.

Life Cycle Assessment is a technique that could help to assess the benefits and drawbacks of polylactic acid. According to The Society of Environmental Toxicology and Chemistry (SETAC), Life Cycle Assessment is "an objective process to evaluate the environmental burdens associated with a product, process, or activity by identifying and quantifying energy and materials used and wastes released to the environment, and to evaluate and implement opportunities to effect environmental improvements (7)." 
Life Cycle Assessment involves three main stages: inventory analysis, impact assessment, and improvement assessment. During these stages an attempt is made to quantify and/or score environmental aspects of resources that are consumed at various stages in manufacture, use and disposal of a product. Also, all of the emissions to air, water and land at each stage are accounted for. These data represent an inventory of all exchanges of substances between product and environment associated with the entire life cycle of the product. A common term used to describe Life Cycle Assessment is "cradle-to-grave" analysis. During the impact assessment, potential contribution of each of these exchanges to important environmental effects (i.e., global warming, photo-chemical smog, fossil fuel depletion) are estimated. Results are then interpreted and recommendations are made (7). Using Life Cycle Assessment will help companies and governments decide whether PLA is an appropriate material for particular products.

\section{Conclusion}

Polylactic acid is a biodegradable polymer made from renewable resources. It is a versatile material with applications in the medical, textile and packaging industries and can be used in anything from sweatshirts to blister packs. It is a material that is creating a lot of interest in the packaging industry for its outstanding properties and earth-friendly biodegradability. Polylactic Acid is a polymer that we will be seeing a lot of in the future, for it is truly an innovation in packaging materials.

\section{References}

1. Biotech Industry S.A. "New-Fill The Implant of the Future." Internet. Available (March 2002) http://www.new-fill.com

2. Cargill Dow. "Company Website." Internet. (2002) Available (April 2002) www.cdpoly.com

3. Datta, R., Tsai, S., Bonsignore, P., Moon, S., and Frank, J.. "Technological and economic potential of poly(lactic acid) and lactic acid derivatives." FEMS Microbiology Reviews, 1995, 16:221-231
4. Drumright, Ray E., Gruber, Patrick R., and Henton, David. "Polylactic Acid Technology." Advanced Materials, 2000, 12(23):1841-1846

5. Grengross, Tillman and Slater, Steven. "How green are green plastics?" Scientific American, 2000, 283(2):36-41

6. Harper, Charles A. Modern Plastics Handbook. New York: McGraw-Hill, 2000

7. Kirkpatrick, Neil. "Life Cycle Assessment." Internet. (2000) Available (August 2001) http://www.residua.com/previous/WB47-LCA.html

8. Lunt, James and Shafer, Andrew. "Polylactic Acid Polymers from Corn: Potential Applications in the Textiles Industry." Internet. Available (April 2002) http://www.cdpoly.com/pdf/lunttech.pdf

9. O'Brien, Michael and Gray, Jennifer. "Federal Trade Commission Announces New Fiber Generic: Cargill Dow's NatureworksTM fibers Receive First Designation of the Century." Internet. (2002) Available (March 2002) http://cargilldow.com/release.. asp?id=92

10. O'Brien, Michael and Mojo, Steve. "New Food Service Alternative for Annually Renewable Resources Unveiled for Use in Major Venues." Internet. (2001) Available (March 2002) www.biocorpusa.com/html/pla_clear_cup.html

11. Shimao, Masayuki. "Biodegradation of plastics." Current opinion in Biotechnology, 2001, $12: 242-247$

12. Stein, Richard. Polymer Recycling: "Opportunities and Limitations." Proceedings of the National Academy of Sciences of the United States of America, 1992, 89(3):835-838

13. Verespej, Michael. "Winning Technologies: Polylactic Polymers." Industry Week, 2000, December 11

14. For more information on the SEBAC technology, visit the SEBAC Web site at: http://plaza.ufl.edu/sifontes/sifontes/ 